\title{
OPEN Metformin improves the outcomes in Chinese invasive breast cancer patients with type 2 diabetes mellitus
}

\begin{abstract}
Tianli Hui ${ }^{1,2}$, Chao Shang ${ }^{1,2}$, Liu Yang ${ }^{1}$, Meiqi Wang ${ }^{1}$, Ruoyang Li $^{1}$ \& Zhenchuan Song ${ }^{1 凶}$
Early reports indicate that metformin, a clinical drug administered to treat type 2 diabetes mellitus (T2DM), was found to be associated with a better prognosis of cancer. The objective of this study was retrospectively analyzed the effect of metformin on the outcomes of Chinese breast cancer patients with T2DM. A total of 3757 primary invasive breast cancer patients who underwent surgery from January 2010 to December 2013 were enrolled. According to the medication treatment, all the patients were divided as non-diabetes group, metformin group and insulin group. The follow-up data for disease-free survival (DFS) and overall survival (OS) were obtained from 3553 patients (median follow up of 85 months) and estimated with the Kaplan-Meier method followed by a log-rank test. Multivariate Cox proportional hazards regression model was applied. The results showed that there was a significant survival difference among non-diabetes group, metformin group and insulin group, 5 -year DFS was $85.8 \%, 96.1 \%, 73.0 \%$, and 5 -year OS was $87.3 \%, 97.1 \%, 73.3 \%$ respectively $(P<0.05)$. Prognostic analysis showed metformin was significantly associated with better DFS and OS. Our results suggested that metformin may have a good effect on the survival of invasive breast cancer patients with T2DM.
\end{abstract}

Breast cancer is one of the most common tumors and the leading cause of cancer-related deaths in women ${ }^{1}$. Type 2 diabetes (T2DM) has also become a growing concern in global public health ${ }^{2}$. A total of 382 million people had diabetes in 2013, and this number is expected to increase to 592 million by $2035^{3}$. T2DM and breast cancer are quite common chronic diseases among women. Data shows that about $16 \%$ of breast cancer patients have diabetes ${ }^{4}$. Epidemiological studies suggest that T2DM may increase the risk of breast cancer and mortality. Women with T2DM have a 23\% higher risk of breast cancer than women without T2DM and have an adverse effect on prognosis ${ }^{5-7}$. Recent research have found that all-cause mortality and breast cancer mortality in breast cancer patients with T2DM increased by $37 \%$ and $17 \%$, respectively ${ }^{8}$.

Metformin is one of the most commonly used anti-diabetic drugs. Due to its anti-cancer properties ${ }^{9}$, it has become increasingly important in the treatment of breast cancer with T2DM recently. One study found that elderly breast cancer patients with diabetes had a better prognosis than those without diabetes. This might be due to the effect of metformin on breast cancer eliminates the adverse effects of diabetes on overall survival ${ }^{10}$. A recent study showed that the use of oral antidiabetic drug metformin can reduce the mortality of breast cancer ${ }^{11}$.

Although the association between T2DM and breast cancer has been extensively studied, there is a lack of research on the relationship between the treatment and control of T2DM and the prognosis of breast cancer patients, particularly in Chinese women. In this study, we retrospectively analyzed a cohort of breast cancer patients with T2DM to evaluate the relationship between the control methods of T2DM and other common clinicopathologic features and prognosis. Therefore, our study analyzed the effect of metformin on the prognosis of breast cancer patients with T2DM, and provided theoretical basis for guiding the treatment of patients and improving the overall survival rate.

\section{Results}

Clinicopathological characteristics. The demographic data and clinicopathological features of metformin group and insulin group were summarized in Table 1. In T2DM group, the age was older, the BMI was smaller, post-menopausal patients was more and the lymph node metastasis rate was lower than that of non- 


\begin{tabular}{|c|c|c|c|c|}
\hline \multirow{2}{*}{$\begin{array}{l}\text { Characteristics } \\
\text { n (\%) }\end{array}$} & Metformin & Insulin & Non-diabetes & \multirow[b]{2}{*}{$P$} \\
\hline & $\mathrm{n}=312$ & $n=79$ & $n=3139$ & \\
\hline \multicolumn{4}{|l|}{ Age at diagnosis } & 0.0001 \\
\hline$\leq 55$ years & $130(41.7)$ & $28(35.4)$ & $2113(67.3)$ & \\
\hline$>55$ years & $182(58.3)$ & $51(64.6)$ & $1026(32.7)$ & \\
\hline \multicolumn{4}{|l|}{ BMI } & 0.0001 \\
\hline$<25$ & $110(35.2)$ & $26(32.9)$ & $1743(55.5)$ & \\
\hline $25-30$ & $150(48.1)$ & 39 (49.4) & $1143(36.4)$ & \\
\hline$\geq 30$ & $52(16.7)$ & $14(17.7)$ & $253(8.1)$ & \\
\hline \multicolumn{4}{|l|}{ Menopausal status } & 0.0001 \\
\hline Pre & $145(46.5)$ & $31(39.2)$ & $2168(69.1)$ & \\
\hline Post & $167(53.5)$ & $48(60.8)$ & $971(30.9)$ & \\
\hline \multicolumn{4}{|l|}{ Tumour size } & 0.0179 \\
\hline$\leq 2 \mathrm{~cm}$ & $137(43.9)$ & $29(36.7)$ & $1499(47.8)$ & \\
\hline$>2 \mathrm{~cm}, \leq 5 \mathrm{~cm}$ & $134(42.9)$ & $41(51.9)$ & $1215(38.7)$ & \\
\hline$>5 \mathrm{~cm}$ & $13(4.2)$ & $5(6.3)$ & $87(2.8)$ & \\
\hline Uncertain & $28(9.0)$ & $4(5.1)$ & $338(10.8)$ & \\
\hline \multicolumn{4}{|c|}{ Lymph node metastasis } & 0.0038 \\
\hline 0 & $200(64.1)$ & $36(45.6)$ & $1832(58.4)$ & \\
\hline $1-3$ & $79(25.3)$ & 25 (31.6) & $744(23.7)$ & \\
\hline $4-9$ & $25(8.0)$ & $11(13.9)$ & $323(10.3)$ & \\
\hline$\geq 10$ & $8(2.6)$ & $7(8.9)$ & $240(7.6)$ & \\
\hline \multicolumn{4}{|l|}{ ER status } & 0.5361 \\
\hline Positive & $244(78.2)$ & $59(74.7)$ & $2367(75.4)$ & \\
\hline Negative & $67(21.5)$ & $20(25.3)$ & $760(24.2)$ & \\
\hline Unknown & $1(0.3)$ & $0(0)$ & $12(0.4)$ & \\
\hline \multicolumn{4}{|l|}{ PR status } & 0.1507 \\
\hline Positive & $223(71.5)$ & $56(70.9)$ & $2084(66.4)$ & \\
\hline Negative & $88(28.2)$ & $23(29.1)$ & $1043(33.2)$ & \\
\hline Unknown & $1(0.3)$ & $0(0)$ & $12(0.4)$ & \\
\hline \multicolumn{4}{|l|}{ HER-2 status } & 0.2143 \\
\hline Positive & $58(18.6)$ & $16(20.3)$ & $692(22.0)$ & \\
\hline Negative & $175(56.1)$ & $51(64.5)$ & $1753(55.8)$ & \\
\hline Uncertain & $79(25.3)$ & $12(15.2)$ & $694(22.1)$ & \\
\hline \multicolumn{4}{|l|}{ Ki-67 } & 0.0056 \\
\hline Low & $105(33.7)$ & $21(26.6)$ & $798(25.4)$ & \\
\hline High & $204(65.4)$ & $58(73.4)$ & $2328(74.2)$ & \\
\hline Uncertain & $3(0.9)$ & $0(0)$ & $13(0.4)$ & \\
\hline \multicolumn{4}{|l|}{ Subtype } & 0.0704 \\
\hline ER-/PR-/HER-2- & $21(6.7)$ & $5(6.3)$ & $310(9.9)$ & \\
\hline ER+/PR+/HER-2- & $154(49.4)$ & $46(58.2)$ & $1443(46.0)$ & \\
\hline HER-2+ & $58(18.6)$ & $16(20.3)$ & $692(22)$ & \\
\hline HER-2 uncertain & $79(25.3)$ & $12(15.2)$ & $694(22.1)$ & \\
\hline
\end{tabular}

Table 1. Patients' characteristics. BMI body mass index, $I D C$ invasive ductal carcinoma, $I L C$ invasive lobular carcinoma, ER estrogen receptor, $P R$ progesterone receptor, HER-2 human epidermal growth factor receptor 2.

diabetes group. In addition, $112(35.9 \%)$ patients were lymphatic metastasis-positive in the metformin group, while 43 (54.4\%) in the insulin group. Besides, in the metformin group, the proportion of older patients (58.3 vs. $64.6 \%)$ and Ki-67 high expression (65.4\% vs. $73.4 \%)$ were lower compared with the insulin group.

Survival analysis. Univariate analysis showed that age, lymph node metastasis and glycemic control methods were significant factors affecting OS and DFS in breast cancer patients with T2DM $(\mathrm{P}<0.05)$ (Table 2).

The Kaplan-Meier OS and DFS curve using log-rank test indicated that the metformin group was significantly different from the insulin group $(P=0.000)$ (Fig. 1A,B). And metformin group had better OS and DFS than insulin group.

In multivariate analysis, metformin was significantly associated with better OS (HR 0.386, 95\% CI $0.248-0.601 ; P=0.000$ ) and DFS (HR 0.384, 95\% CI 0.247-0.598; $P=0.000$ ). Meanwhile, multivariate analysis also showed that younger age, no lymph node metastasis were associated with a good prognosis $(\mathrm{P}<0.05)($ Table 2$)$. 


\begin{tabular}{|c|c|c|c|c|}
\hline \multirow[b]{2}{*}{ Evaluated factors } & \multicolumn{2}{|l|}{ Multivariable (OS) } & \multicolumn{2}{|l|}{ Multivariable (DFS) } \\
\hline & HR $(95.0 \%$ CI) & $P$ & HR(95.0\% CI) & $P$ \\
\hline Age at diagnosis & & 0.003 & & 0.013 \\
\hline$\leq 55$ years & 1 & & 1 & \\
\hline$>55$ years & $1.302(1.094-1.549)$ & & $1.247(1.048-1.484)$ & \\
\hline BMI & & 0.000 & & 0.000 \\
\hline$<25$ & 1 & & 1 & \\
\hline $25-30$ & $1.280(1.070-1.532)$ & & $1.300(1.087-1.556)$ & \\
\hline$\geq 30$ & $1.696(1.300-2.213)$ & & $1.753(1.344-2.286)$ & \\
\hline Tumour size & & 0.000 & & 0.000 \\
\hline$\leq 2 \mathrm{~cm}$ & 1 & & 1 & \\
\hline$>2 \mathrm{~cm}, \leq 5 \mathrm{~cm}$ & $1.261(1.053-1.511)$ & & $1.259(1.051-1.507)$ & \\
\hline$>5 \mathrm{~cm}$ & $2.281(1.602-3.247)$ & & $2.234(1.569-3.182)$ & \\
\hline Uncertain & $1.248(0.897-1.736)$ & & $1.241(0.892-1.726)$ & \\
\hline Lymph node metastasis & & 0.000 & & 0.000 \\
\hline 0 & 1 & & 1 & \\
\hline $1-3$ & $2.684(2.158-3.338)$ & & $2.716(2.184-3.376)$ & \\
\hline $4-9$ & $3.960(3.072-5.105)$ & & $4.096(3.178-5.280)$ & \\
\hline$\geq 10$ & $9.264(7.339-11.695)$ & & $9.837(7.782-12.433)$ & \\
\hline ER status & & 0.012 & & 0.016 \\
\hline Negative & 1 & & 1 & \\
\hline Positive & $0.738(0.563-0.967)$ & & $0.738(0.563-0.967)$ & \\
\hline Unknown & - & & - & \\
\hline PR status & & 0.025 & & 0.017 \\
\hline Negative & 1 & & 1 & \\
\hline Positive & $0.745(0.580-0.958)$ & & $0.730(0.569-0.938)$ & \\
\hline Unknown & - & & - & \\
\hline Ki-67 & & 0.009 & & 0.007 \\
\hline Low & 1 & & 1 & \\
\hline High & $1.255(1.017-1.547)$ & & $1.285(1.042-1.584)$ & \\
\hline Uncertain & - & & - & \\
\hline Groups & & 0.000 & & 0.000 \\
\hline Non-diabetes & 1 & & 1 & \\
\hline Metformin & $0.386(0.248-0.601)$ & & $0.384(0.247-0.598)$ & \\
\hline Insulin & $1.307(0.848-2.014)$ & & $1.205(0.781-1.858)$ & \\
\hline
\end{tabular}

Table 2. Multivariable Cox analyses of clinical features on OS and DFS in patients with T2DM.

A

Breast Cancer Overall Survival Rates by Medication Treatment

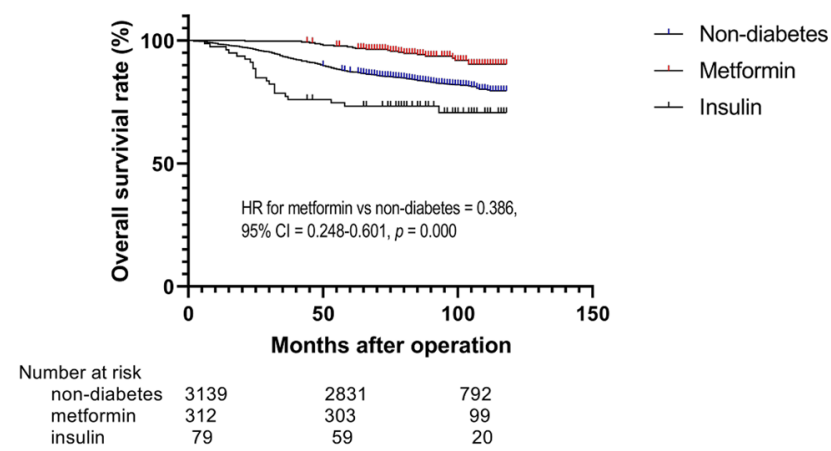

B

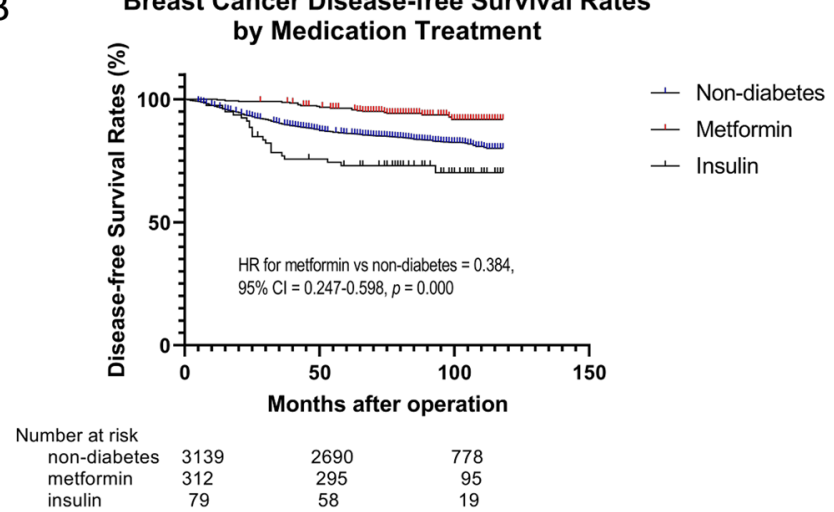

Figure 1. Kaplan-Meier survival estimate for OS (A) and DFS (B). DFS disease-free survival, OS overall survival. 


\section{Discussion}

Breast cancer is the most common cancer among women worldwide and the second leading cause of cancer death ${ }^{12,13}$. T2DM is one of the most common chronic diseases and has become a health issue of increasing concern worldwide ${ }^{14,15}$. Breast cancer combined with T2DM seriously affects women's physical and mental health. Our retrospective analysis showed that metformin had beneficial effects on OS and DFS in breast cancer patients with T2DM. This is consistent with some reports in the literature. One study found that the use of metformin can reduce the all-cause mortality of breast cancer patients with $\mathrm{T} 2 \mathrm{DM}^{16}$. A retrospective analysis pointed out that diabetic patients with breast cancer receiving metformin and neoadjuvant chemotherapy have a higher pathologic complete response rate than do diabetics not receiving metformin ${ }^{17}$. Another study found that patients with HER2-positive breast cancer with diabetes had better clinical outcomes after treatment with metformin than patients without metformin ${ }^{18}$. The study by Bayraktar et al., confirmed that although metformin did not improve the survival rate of patients with triple negative breast cancer, the trend of recurrence and metastasis was reduced compared with women without diabetes ${ }^{19}$. In addition, some studies have pointed out that high insulin levels are associated with increased breast cancer risk and poor prognosis. And the use of metformin can lower blood sugar and insulin levels, thereby inhibiting cancer cell proliferation and tumor growth ${ }^{20,21}$. In this study, it was also observed that the prognosis of the metformin group was significantly better than that of the insulin group.

How does metformin play an anti-cancer role? First, metformin can directly act on cancer cells through the protein kinase pathway activated by AMP (adenosine monophosphate), inhibiting downstream signaling of mammalian target rapamycin (a key growth factor), thereby inhibiting cell growth and proliferation ${ }^{22,23}$. Second, metformin can also reduce the activation of insulin/IGF-1 (insulin-like growth factor 1) receptors in tumor cells, resulting in reduced stimulation of the mitogenic pathway, thereby indirectly inhibiting cell proliferation, tumor formation and metastasis ${ }^{24,25}$. And recent studies have also found that metformin increased the number of $\mathrm{CD}^{+}$tumor-infiltrating lymphocytes (TILS) behavioring anti-cancer effect in the tumor microenvironment ${ }^{26,27}$.

As we all known, premenopausal breast cancer patients usually have a poor prognosis, but the prognosis of premenopausal patients (under 55 years old in this study) is relatively better, which may be due to the fact that most of premenopausal patients with T2DM using metformin in our study. One study pointed out that older women are less likely to receive active treatment than younger breast cancer patients, thus leading to a poorer prognosis $^{28}$.

In conclusion, our study provided some support for the use of metformin may improve the prognosis of breast cancer patients with T2DM. However, our research has certain limitations, so these results should be carefully considered. In the future, a large number of prospective studies are needed to verify the effect of metformin on breast cancer patients to analyze the impact on the prognosis.

\section{Methods}

Study design and patients. A consecutive series of operable breast cancer patients from a single center was included. National guidelines were followed appropriately for the adjuvant therapy prescription. The study was approved by the Ethic Committee of the Fourth Hospital of Hebei Medical University. Informed consent for this study from all patients or relatives had been obtained during initial follow up. The present research was performed in accordance with relevant guidelines and regulations.

A total of 3757 patients with primary invasive breast cancer were identified at the Breast Center of the Fourth Hospital of Hebei Medical University from January 2010 to December 2013. Patients who were diagnosed with bilateral tumors or distant metastases at the preoperative workup were excluded. A total of 3553 patients were enrolled in the final analysis, including 414 breast cancer patients with T2DM and 3139 non-diabetic breast cancer patients. We divided 414 breast cancer patients with T2DM into metformin group (312), insulin group (79), diet and exercise group (23) according to the treatment of T2DM (Fig. 2).

Oral metformin medication was defined as the metformin group, and insulin therapy was defined as the insulin group. Most patients obeyed the medication well between them during the follow-up period. However, there were a small number of patients (both no more than 10\%) who were simultaneously treated with other oral hypoglycemic drugs, such as sulfonylureas (gliclazone, glimepiride), glinides (repaglinide), a glucosidase inhibitor (Acarbose), etc. Those who did not undergo drug treatment and relied on diet change and exercise enhancement were defined as diet and exercise group. And this group of patients was basically in the early stage of T2DM.

Diagnostic criteria for T2DM (according to the WHO Diabetes Expert Committee, 1999) are as follows, fasting blood glucose $(\mathrm{FPG}) \geq 7.0 \mathrm{mmol} / \mathrm{L}$, blood glucose $2 \mathrm{~h}$ after glucose load $(2 \mathrm{~h} \mathrm{PG}) \geq 11.1 \mathrm{mmol} / \mathrm{L}$, or random blood glucose $\geq 11.1 \mathrm{mmol} / \mathrm{L}^{29}$. The diagnosis was made based on the patient's fasting blood glucose level at the time of the first operation, history of a second-level or higher hospital diagnosis and oral hypoglycemic drugs, plus symptoms such as polyuria, polydipsia, polydipsia, weight loss.

Tumor characteristics. Pathological information from all patients was obtained from the Department of Pathology at the Fourth Hospital of Hebei Medical University. Following American Society of Clinical Oncology/College of American Pathologists Guideline Recommendations, Estrogen receptor (ER) and progestogen receptor (PR) positive disease were defined by immunohistochemical (IHC) staining of $>1 \%$ of cells $\mathrm{s}^{30}$. HER2positive was defined by HER2 protein expression IHC $3+$ positive and if HER2 was 2+ positive on IHC, we performed immunofluorescence hybridization (FISH) for HER2. FISH was positive if the average HER2 gene copy number $\geq 6.0$ signals/cell or HER2/CEP17 ratio $\geq 2.0^{31}$. Ki-67 expression was categorized as low $(\leq 15 \%)$ and high $(>15 \%)$. Histology type was determined according to the World Health Organization classification ${ }^{32}$.

Follow-up. The starting point was the date of operation, and all ended on December 30, 2019. As we reported previously $^{33}$. For patients who died, the date and cause of death were recorded, and all deaths not attributable 


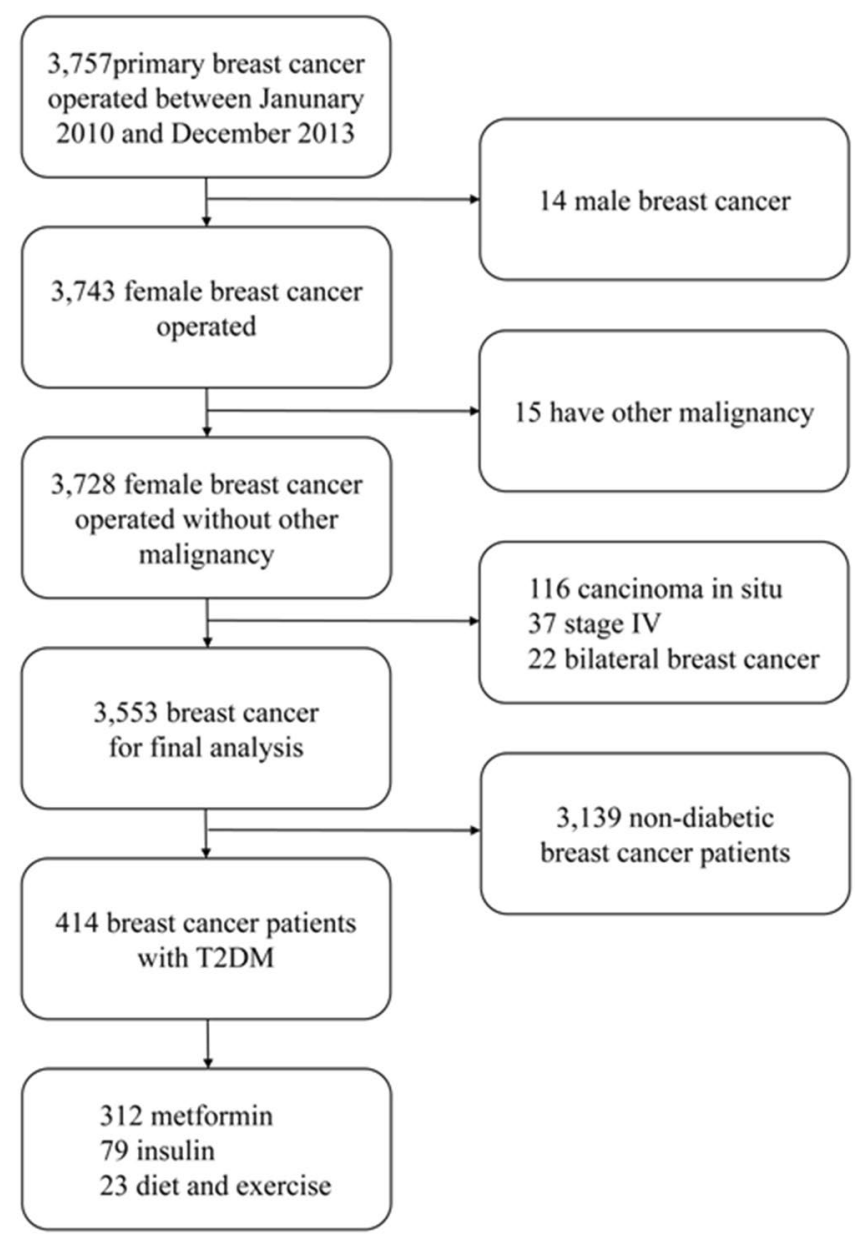

Figure 2. Flow chart of patient selection for final analysis.

to breast cancer were censored at the date of death. DFS was calculated from the date of operation to the first observed recurrence (local or distant), and patients without recurrence were censored at the time of last followup or death. OS was defined from the date of operation to death from any cause scored as an event. Patients who were still alive at the time of last follow-up were censored. Accordingly, the primary endpoints were DFS and OS.

Data analysis. The SPSS 21.0 statistical software (IBM, New York City, NY) was applied for statistical analysis. The distribution of categorical variables was compared using the standard $\chi^{2}$ test between metformin and insulin groups. Survival curves were constructed with the Kaplan-Meier method, and log-rank test for difference analysis. The univariate and multivariate Cox regression models were used to determine the association of clinical pathological features and the prognosis of different groups with DFS and OS. Hazard ratios (HRs) for DFS and OS were estimated using a Cox proportional hazards regression through multivariate analysis. Survival rates and HRs were presented with their $95 \%$ confidence intervals $(\mathrm{CI}) . \mathrm{P}<0.05$ was considered as a significant difference.

Received: 14 December 2020; Accepted: 27 April 2021

Published online: 11 May 2021

\section{References}

1. Torre, L. A. et al. Global cancer statistics, 2012. CA Cancer J. Clin. 65, 87-108. https://doi.org/10.3322/caac.21262 (2015).

2. Corriere, M., Rooparinesingh, N. \& Kalyani, R. R. Epidemiology of diabetes and diabetes complications in the elderly: An emerging public health burden. Curr. Diabetes Rep. 13, 805-813. https://doi.org/10.1007/s11892-013-0425-5 (2013).

3. Guariguata, L. et al. Global estimates of diabetes prevalence for 2013 and projections for 2035. Diabetes Res. Clin. Pract. 103, 137-149. https://doi.org/10.1016/j.diabres.2013.11.002 (2014).

4. Wolf, I., Sadetzki, S., Catane, R., Karasik, A. \& Kaufman, B. Diabetes mellitus and breast cancer. Lancet Oncol. 6, 103-111. https:// doi.org/10.1016/s1470-2045(05)01736-5 (2005).

5. De Bruijn, K. M. et al. Systematic review and meta-analysis of the association between diabetes mellitus and incidence and mortality in breast and colorectal cancer. Br. J. Surg. 100, 1421-1429. https://doi.org/10.1002/bjs.9229 (2013).

6. Srokowski, T. P., Fang, S., Hortobagyi, G. N. \& Giordano, S. H. Impact of diabetes mellitus on complications and outcomes of adjuvant chemotherapy in older patients with breast cancer. J. Clin. Oncol. 27, 2170-2176. https://doi.org/10.1200/jco.2008.17. 5935 (2009). 
7. Peairs, K. S. et al. Diabetes mellitus and breast cancer outcomes: A systematic review and meta-analysis. J. Clin. Oncol. 29, 40-46. https://doi.org/10.1200/jco.2009.27.3011 (2011).

8. Zhou, Y., Zhang, X., Gu, C. \& Xia, J. Influence of diabetes mellitus on mortality in breast cancer patients. ANZ J. Surg. 85, 972-978. https://doi.org/10.1111/ans.12877 (2015).

9. Noto, H., Goto, A., Tsujimoto, T. \& Noda, M. Cancer risk in diabetic patients treated with metformin: A systematic review and meta-analysis. PLoS ONE 7, e33411. https://doi.org/10.1371/journal.pone.0033411 (2012).

10. Kiderlen, M. et al. Diabetes in relation to breast cancer relapse and all-cause mortality in elderly breast cancer patients: A FOCUS study analysis. Ann. Oncol. 24, 3011-3016. https://doi.org/10.1093/annonc/mdt367 (2013).

11. Haukka, J., Niskanen, L. \& Auvinen, A. Risk of cause-specific death in individuals with cancer-modifying role diabetes statins and metformin. Int. J. Cancer 141, 2437-2449. https://doi.org/10.1002/ijc.31016 (2017).

12. Bray, F. et al. Global cancer statistics 2018: GLOBOCAN estimates of incidence and mortality worldwide for 36 cancers in 185 countries. CA Cancer J. Clin. 68, 394-424. https://doi.org/10.3322/caac.21492 (2018).

13. Liao, S. et al. Association between diabetes mellitus and breast cancer risk: A meta-analysis of the literature. Asian Pac. J. Cancer Prev. 12, 1061-1065 (2011).

14. Al-Lawati, J. A. Diabetes mellitus: A local and global public health emergency!. Oman Med. J. 32, 177-179. https://doi.org/10. 5001/omj.2017.34 (2017).

15. Misra, A. et al. Diabetes in developing countries. J. Diabetes 11, 522-539. https://doi.org/10.1111/1753-0407.12913 (2019).

16. Yang, T., Yang, Y. \& Liu, S. Association between metformin therapy and breast cancer incidence and mortality: Evidence from a meta-analysis. J. Breast Cancer 18, 264-270. https://doi.org/10.4048/jbc.2015.18.3.264 (2015).

17. Jiralerspong, S. et al. Metformin and pathologic complete responses to neoadjuvant chemotherapy in diabetic patients with breast cancer. J. Clin. Oncol. 27, 3297-3302. https://doi.org/10.1200/jco.2009.19.6410 (2009).

18. He, X. et al. Metformin and thiazolidinediones are associated with improved breast cancer-specific survival of diabetic women with HER2+ breast cancer. Ann. Oncol. 23, 1771-1780. https://doi.org/10.1093/annonc/mdr534 (2012).

19. Bayraktar, S. et al. Effect of metformin on survival outcomes in diabetic patients with triple receptor-negative breast cancer. Cancer 118, 1202-1211. https://doi.org/10.1002/cncr.26439 (2012).

20. Hatoum, D. \& McGowan, E. M. Recent advances in the use of metformin: Can treating diabetes prevent breast cancer?. Biomed. Res. Int. 2015, 548436. https://doi.org/10.1155/2015/548436 (2015).

21. Gonzalez-Angulo, A. M. \& Meric-Bernstam, F. Metformin: A therapeutic opportunity in breast cancer. Clin. Cancer Res. 16, 1695-1700. https://doi.org/10.1158/1078-0432.Ccr-09-1805 (2010).

22. Dowling, R. J., Zakikhani, M., Fantus, I. G., Pollak, M. \& Sonenberg, N. Metformin inhibits mammalian target of rapamycindependent translation initiation in breast cancer cells. Cancer Res. 67, 10804-10812. https://doi.org/10.1158/0008-5472.Can-072310 (2007).

23. Zakikhani, M., Dowling, R., Fantus, I. G., Sonenberg, N. \& Pollak, M. Metformin is an AMP kinase-dependent growth inhibitor for breast cancer cells. Cancer Res. 66, 10269-10273. https://doi.org/10.1158/0008-5472.Can-06-1500 (2006).

24. Belfiore, A., Frasca, F., Pandini, G., Sciacca, L. \& Vigneri, R. Insulin receptor isoforms and insulin receptor/insulin-like growth factor receptor hybrids in physiology and disease. Endocr. Rev. 30, 586-623. https://doi.org/10.1210/er.2008-0047 (2009).

25. Frasca, F. et al. The role of insulin receptors and IGF-I receptors in cancer and other diseases. Arch. Physiol. Biochem. 114, $23-37$. https://doi.org/10.1080/13813450801969715 (2008).

26. Ma, R., Yi, B., Riker, A. I. \& Xi, Y. Metformin and cancer immunity. Acta Pharmacol. Sin. 41, 1403-1409. https://doi.org/10.1038/ s41401-020-00508-0 (2020).

27. Eikawa, S. et al. Immune-mediated antitumor effect by type 2 diabetes drug, metformin. Proc. Natl. Acad. Sci. U.S.A. 112, 18091814. https://doi.org/10.1073/pnas.1417636112 (2015).

28. Schonberg, M. A. et al. Breast cancer among the oldest old: Tumor characteristics, treatment choices, and survival. J. Clin. Oncol. 28, 2038-2045. https://doi.org/10.1200/jco.2009.25.9796 (2010).

29. Tominaga, M. Diagnostic criteria for diabetes mellitus. Rinsho Byori 47, 901-908 (1999).

30. Hammond, M. E. et al. American Society of Clinical Oncology/College of American Pathologists guideline recommendations for immunohistochemical testing of estrogen and progesterone receptors in breast cancer (unabridged version). Arch. Pathol. Lab. Med. 134, e48-72. https://doi.org/10.1043/1543-2165-134.7.e48 (2010).

31. Wolff, A. C. et al. Recommendations for human epidermal growth factor receptor 2 testing in breast cancer: American Society of Clinical Oncology/College of American Pathologists clinical practice guideline update. J. Clin. Oncol. 31, 3997-4013. https://doi. org/10.1200/jco.2013.50.9984 (2013).

32. Tan, P. H. et al. The 2019 World Health Organization classification of tumours of the breast. Histopathology 77, 181-185. https:// doi.org/10.1111/his.14091(2020).

33. Wang, X. et al. Body mass index at diagnosis as a prognostic factor for early-stage invasive breast cancer after surgical resection. Oncol. Res. Treat. 42, 195-201. https://doi.org/10.1159/000496548 (2019).

\section{Author contributions}

T.H. and C.S. wrote the main manuscript text; C.S., L.Y. and R.L. collected and arranged patients' data; T.H. and M.W. conducted statistical analysis; Z.S. supported quality management and directed team.

\section{Funding}

The study was supported by a grant from the Hebei Science and Technology Agency (17272604D), Natural Science Foundation of Hebei Province (H2020206365), Special Fund for Clinical Research of Wu Jieping Medical Foundation (320.6750.2020-07-17), and Beijing Xisike Clinical Oncology Research Funddtion (Y-SY2019010021). The funding bodies had no role in study design, collection, analysis, or interpretation of data, or in writing the manuscript.

\section{Competing interests}

The authors declare no competing interests.

\section{Additional information}

Correspondence and requests for materials should be addressed to Z.S.

Reprints and permissions information is available at www.nature.com/reprints.

Publisher's note Springer Nature remains neutral with regard to jurisdictional claims in published maps and institutional affiliations. 
(c) (i) Open Access This article is licensed under a Creative Commons Attribution 4.0 International cc) License, which permits use, sharing, adaptation, distribution and reproduction in any medium or format, as long as you give appropriate credit to the original author(s) and the source, provide a link to the Creative Commons licence, and indicate if changes were made. The images or other third party material in this article are included in the article's Creative Commons licence, unless indicated otherwise in a credit line to the material. If material is not included in the article's Creative Commons licence and your intended use is not permitted by statutory regulation or exceeds the permitted use, you will need to obtain permission directly from the copyright holder. To view a copy of this licence, visit http://creativecommons.org/licenses/by/4.0/.

(C) The Author(s) 2021 